\title{
Effects of factual information on creating resistance to emotional appeals'
}

SAMUEL HIMMELFARB and JOHN YOUNGBLOOD, University of Massachusetts, Amherst, Mass. 01002

Factual information about a little-known country was presented to Ss who subsequently heard either a negative or positive emotional appeal about the country and its people. Ss in the control conditions did not receive prior information about the country before hearing the emotional appeals. The results indicated that Ss exposed to prior factual information were less persuaded by the negative appeal than Ss who did not receive prior information. Prior factual information had little effect in influencing susceptibility to the positive appeal. Indirect evidence cited suggested that the factual information tended to create a positive attitude toward the country. Several interpretations of the data, including an averaging model of information integration, were discussed.

Lewan \& Stotland (1961) found that Ss exposed to prior factual information about a little-known country were persuaded less by a subsequent negative appeal than Ss who did not receive prior information about the country. They suggested two alternative explanations for the effects of factual information in creating resistance to a subsequent negative appeal. (1) Information creates a cognitive structure about the attitude object and anchors the attitude toward the object. Subsequent information is related to the existing cognitive structure and any changes in the evaluation of the attitude object inconsistent with the existing structure are resisted. (2) Information creates greater familiarity and positive identification with the attitude object, thereby producing resistance to subsequent negative information. Lewan and Stotland argued that if the first explanation were correct, then prior information should make one less susceptible to either negative or positive information. If the latter explanation were the correct one, then prior information should produce resistance only to a negative appeal. Increased familiarity with the attitude object might even facilitate change toward the attitude object.

The present study investigated the influence of prior factual information on producing resistance to a positive as well as to a negative emotional appeal.

\section{SUBJECTS}

Introductory psychology students at the University of Massachusetts served as Ss in groups varying in size up to 10 . The experiment was conducted by a number of undergraduate Es each of whom ran Ss in all of the experimental conditions. Ss were randomly assigned to Es and to the four experimental conditions. The data reported are from the $41 \mathrm{Ss}$ remaining in each of the four conditions after the data from Ss with incomplete questionnaires were discarded and the cell sizes were randomly equalized.

\section{PROCEDURE}

Each $S$ received a booklet which contained a two-page factual communication about one of two countries. The information was obtained from encyclopedic sources and was edited to remove evaluative content. Ss in the prior information conditions received a communication about the country and people of Andorra, and Ss in the control conditions received a communication about Etruria.

Immediately after reading the written communication, Ss heard a tape-recording of a two-page evaluative appeal read in an emotional tone about the country of Andorra and the Andoresse people. Ss either heard a negative appeal lambasting the Andoresse or a positive appeal extolling their virtues. The communications were designed to conform as closely as possible to the communications described by Lewan \& Stotland (1961). Both the written and oral communications were introduced as part of a study evaluating different methods of presenting material about geography to students and each statement was attributed to a different Professor of Geography.

After listening to one of the taped emotional appeals, Ss were tested for their recall of the information in the written communication. Ss then evaluated the written communication and its writer, and the oral communication and its speaker. Finally, attitudes toward the people of Andorra, Etruria, and two additional countries were measured on 16 7-point bipolar adjective scales.

\section{RESULTS}

The attitude scales used had a possible range of 16-112 with a neutral point at 64 . Table 1 gives the mean attitude scores toward the Andoresse-the object of the emotional appeals-in the four experimental conditions. The analysis of variance performed on the data yielded a significant main effect for type of appeal $(F=332.09$, MSerror $=318.52, d f=1 / 160$, $\mathrm{p}<.0001)$. The main effect of prior information was significant also $(F=6.37, \mathrm{df}=1 / 160, p<.025)$, but appears to be due to the significant interaction effect $(F=14.39$, $\mathrm{df}=1 / 160, \mathrm{p}<.001$ ). The means in Table 1 show the nature of the interaction effect. When Ss received prior information about the Andoresse and then heard the negative appeal their attitudes were less negatively polarized than if they did not receive prior information $(t=4.47, \mathrm{df}=80, \mathrm{p}<.0001)$. However, there was no difference between Ss who received and did not receive prior information about Andorra in the degree to which their attitudes were polarized in the positive direction after hearing the positive appeal $(t<1, \mathrm{df}=80)$.

Attitude scores toward Etruria also were obtained and the mean scores for the four conditions are presented in Table 2. The analysis of variance performed on these data showed that Ss who received factual information about Etruria had a more positive attitude toward Etruria than Ss who received factual information about Andorra $(F=88.78$, MSerror $=124.98$, $\mathrm{df}=1 / 160, p<.0001)$. Type of emotional appeal about Andorra had no influence on attitudes toward Etruria nor did the two variables interact to any significant degree.

Table 1

Mean Attitude Scores Toward Andoresse

\begin{tabular}{lcc}
\hline \multirow{2}{*}{$\begin{array}{c}\text { Factual Information } \\
\text { about Andorra }\end{array}$} & \multicolumn{2}{c}{$\begin{array}{c}\text { Subsequent Emotional Appeal } \\
\text { about Andorra }\end{array}$} \\
\cline { 2 - 3 } & Negative & Positive \\
\hline Prior Information & 50.78 & 91.00 \\
No Prior Information & 33.17 & 94.54 \\
\hline
\end{tabular}

Table 2

Mean Attitude Scores Toward Etnuria

\begin{tabular}{lcc}
\hline \multirow{2}{*}{$\begin{array}{c}\text { Factual Information } \\
\text { about Etruria }\end{array}$} & \multicolumn{2}{c}{$\begin{array}{c}\text { Subsequent Emotional Appeal } \\
\text { about Andorra }\end{array}$} \\
\cline { 2 - 3 } & Negative & Positive \\
\hline No Prior Information & 70.90 & 70.15 \\
Prior Information & 89.44 & 84.51 \\
\hline
\end{tabular}




\section{DISCUSSION}

The results indicated that prior factual information about an attitude object reduced susceptibility to subsequent negative information about the object. This finding is in agreement with the results obtained by Lewan \& Stotland (1961). Their study used a pretest-posttest design in which the initial measure of attitude was obtained immediately after presentation of the factual information. Their results, therefore, were subject to the alternative interpretation that prior information followed by an initial measurement of attitude cued Ss about the purpose of the study and created some resistance to the subsequent negative appeal. The present study, which used a posttest-only design, effectively rules out this interpretation and the locus of the resistance effect must be sought in the effects of prior information.

Prior factual information produced no significant resistance to a subsequent positive appeal. Lewan and Stotland argued that the cognitive structure explanation would predict resistance to both negative and positive appeals as a result of the prior information, but that the familiarity-identification explanation would predict that prior information creates resistance to only negative information. However, it cannot be concluded that the data favor the familiarity-identification hypothesis, since there exists yet another explanation for the obtained results.

The alternative explanation for the effects of prior information in creating resistance to subsequent information stems from some of the current research on impression formation. In studies of impression formation, Ss have no prior information about the person before entering the experiment. In this respect, the impression formation paradigm is very similar to the present attitude change situation. Studies of impression formation have indicated that the process by which divergent bits of information are integrated into an overall judgment can be modeled quite accurately by an averaging formulation (Anderson, 1962, 1965; Himmelfarb \& Senn, in press). Provided that the factual information was less polarized than the emotional appeals, an averaging model would predict that Ss exposed to prior information would have a less polarized attitude following presentation of an emotional appeal than Ss not exposed to the prior information.

Qualitatively, an averaging formulation could account for both Lewan and Stotland's and the present findings with respect to negative appeals. The results in the positive appeal conditions also could be accounted for by the averaging interpretation if the factual information produced positive affect toward the attitude object rather than merely conveying neutral information about the object. To be in full accord with the present data, the attitude produced by the factual information would have to be sufficiently positive so that the average of the evaluations produced by it and the positive appeal would not be significantly different from that produced by the positive appeal by itself.

What evidence is there that the factual information did produce a positive evaluation toward the attitude object? Lewan and Stotland found no difference between their two information conditions on the initial attitude measure obtained subsequent to exposure to the factual information. Therefore, they concluded that their factual information was neutral information. Inspection of their data, however, reveals that both information conditions were above the theoretical neutral point of their attitude scale with the prior information condition having a slightly, but not significantly, higher attitude. The effects of the factual information cannot be directly assessed in the present study because of the absence of a group which received only the factual information. Indirectly, there is some evidence which suggests that factual information may produce a positive attitude.
Youngblood (1968), following up the study reported here, presented Ss with factual information taken from the factual communication about Andorra used in this study (which in turn was highly similar to the material used by Lewan and Stotland). Youngblood's factual information had been judged by an independent group of Ss to be neither favorable nor unfavorable toward the country. Nevertheless, this information produced a more positive attitude toward the country than the attitudes held by Ss who received no information about the country. These data suggest that factual information of the type used in these studies does produce positive affective responses toward the attitude object.

Zajonc (1968) recently has advanced the general hypothesis that mere repeated exposure to an object produces a positive attitude toward it. In support of this hypothesis, Zajonc presented data from a series of studies in which frequency of exposure to stimuli such as nonsense words, pseudo-Chinese letters, and photographs of persons was experimentally manipulated. The results indicated a positive relationship between frequency of exposure and attitude toward these objects. Thus, familiarity with even a neutral object can create a positive attitude toward the object.

If factual information does create a positive attitude, was the attitude created sufficiently positive so that the average of the evaluations produced by the factual information and the positive appeal was not statistically different from the attitude produced by the positive appeal alone? Rough calculations will show that the response on the attitude scale produced by the factual information need only be approximately 80 in order that the average would not deviate significantly from the mean obtained in the positive appeal condition. The results presented in Table 2 indicate that the factual information about Etruria produced an attitude toward Etruria which was 86.98 , on the average. To the extent that the attitudes produced by both sets of factual information were roughly comparable, the latter data suggest that the factual information could have produced a positive attitude of sufficient strength so as to account for the lack of a statistically significant difference between the two information conditions receiving the positive appeal.

More generally, the averaging formulation generates predictions similar to that made by Lewan and Stotland's cognitive structure hypothesis, but there are differences between the two interpretations. Qualitatively, it makes little difference to the averaging formulation whether the prior factual information produces a neutral or moderately positive attitude; attitudes following presentation of the initial plus the subsequent information should lie in between attitudes produced by the two separate sets of information. The cognitive structure hypothesis, at least as advanced by Lewan and Stotland, seems predicated on the assumption that the prior information produced a cognitive structure free from affect toward the attitude object. The order in which the factual and emotional information is presented should make no difference if the simple averaging model is correct but may have consequences for the cognitive structure hypothesis. Youngblood (1968) found no difference between factualemotional and emotional-factual orders of presentation. In addition, the cognitive structure explanation seems to imply an active process of resistance, while the averaging formulation would view the apparent resistance effect of prior information as a result of the pooling of two discrepant pieces of information.

The averaging model also provides a more precise theoretical framework than does the cognitive structure explanation. The former specifies how differences in information are related to each other, while the latter explanation merely suggests that subsequent information is related to the existing structure and is resisted to the extent that the information is incompatible 
whether the distractor word would be a homphone, synonym or unrelated word (although Ss did know that the distractor would be one of these). Since only semantic information would be distinctive for recognition of homophones while only phonetic information would be distinctive for recognition of synonyms, less relevant information would be available for recognition of synonyms or homophones than of unrelated words (where both phonetic and semantic information would be distinctive), so that recognition of homophones and synonyms would be less accurate. Decreased recognition when the distractor word was a synonym or homophone rather than an unrelated word suggests that both phonetic and semantic information were encoded, rather than information directly about the word as a functional unit.

For discrimination of paired presentations it appears that Ss may selectively encode either semantic information for homophones or phonetic information for synonyms, so that all information retained on paired presentation would be relevant, resulting in the same discrimination of homophones and synonyms as of unrelated words. This seems reasonable, since on paired presentations Ss would know at the time of presentation that only semantic information would be relevant for homophones and that only phonetic information would be relevant for synonyms. The finding that discrimination of homophones and synonyms is the same as discrimination of unrelated words for paired presentation suggests that these results indicate encoding and retention of phonetic and semantic information, rather than confusions in identification due to phonetic or semantic similarity. Such confusion should cause less accurate identification of homophones or synonyms for paired presentation as well as for single presentation.

The decrease in identification of unrelated words for paired presentation compared with identification for single presentation indicates that Ss did follow instructions by attending to both words presented, and apparently may have retained some information about the distractor as well as underlined words. This could account for the finding that identification of homophones and synonyms was the same for paired and single presentation, even though only information relevant for discrimination was encoded on paired presentation while for single presentations only part of the information encoded would be relevant for recognition.

The present findings indicate that both phonetic and semantic information about English words may be encoded and retained for forced-choice recognition and discrimination and that either semantic or phonetic information may be selectively stored, at least when Ss know that such information is relevant. The total amount of information retained for such recognition and discrimination may remain constant. It seems remarkable that recognition of synonyms and homophones does not differ under the present conditions, since recent work indicates that longer-term memory may retain principally semantic information (Kintsch \& Buschke, 1968), suggesting that recognition of synonyms might be decreased more than recognition of homophones. It is possible that recognition of synonyms might be poorer than recognition of homophones if Ss did not know at the time of single presentations that phonetic and semantic information would be equally relevant for such forced-choice recognition. These results, suggesting that information encoded for verbal recognition and discrimination may be information about semantic and phonetic attributes of words, seem consistent with the hypothesis discussed by Anisfeld \& Knapp (1968) that words may exist in permanent storage as complexes of features, and the possibility that words are generated by the operation of linguistic rules.

\section{REFERENCES}

ANISFELD, M., \& KNAPP, M. Association, synonymity, and directionality in false recognition. Journal of Experimental Psychology, 1968, 77, 171-179.

KINTSCH, W., \& BUSCHKE, H. Homophones and synonyms in short-term memory. Journal of Experimental Psychology, in press.

THORNDIKE, E. L., \& LORGE, I. The teacher's wordbook of 30,000 words. New York: Teacher's College, Columbia University, Bureau of Publications, 1944.

UNDERWOOD, B. J. False recognition by implicit verbal responses. Journal of Experimental Psy chology, 1965, 70, 122-129.

UNDERWOOD, B. J., \& FREUND, J. S. Errors in recognition learning and retention. Journal of Experimental Psychology, 1968, 78, 55-63. NOTES

1. This investigation was supported by United States Public Health Service Research Grant MH-08556 and United States Public Health Service Research Scientist Development Award 5-K 1-Mh-23,796 from the National Institute of Mental Health to Herman Buschke. The assistance of Jo Ann Wallace and Lynda Snavely is gratefully acknowledged.

2. Because of ty pographical errors, two of the homophone pairs could not be tested, so there were 48 sets of homophones with paired presentation instead of 50 .

3. Table 2 gives the means of the observed percentage of correct responses $(\mathrm{Po})$ when corrected $(\mathrm{Pc})$ for guessing $(\mathrm{G}=50 \%)$ for each $\mathrm{S}$ by a conventional adjustment: $P c=(P o-G) / 100-G$.

\section{(Continued from page 268)}

with it. The averaging model also generates quantitative predictions about the responses to the sets of information. Since quantitative predictions depend to an extent on an adequate scaling of the information, a more precise test of the averaging model was not possible in the present study. The adequacy of the model in handling the effects of neutral information is currently being tested in an impression formation paradigm.

\section{REFERENCES}

ANDERSON, N. H. Application of an additive model to impression formation. Science, $1962,138,817-818$.

ANDERSON, N. H. Averaging versus adding as a stimulus-combination rule in impression formation. Journal of Experimental Psychology, $1965,70,394-400$.
HIMMELFARB, S., \& SENN, D. J. Forming impressions of social class: Two tests of an averaging model. Journal of Personality \& Social Psychology, in press.

LEWAN, P. C., \& STOTLAND, E. The effects of prior information on susceptibility to an emotional appeal. Journal of Abnormal \& Social Psychology, 1961, 62, 450-453.

YOUNGBLOOD, J. Effects of prior neutral information on attitude change. Unpublished Master's thesis, University of Massachusetts, 1968.

ZAJONC, R. B. Attitudinal effects of mere exposure. Journal of Personality \& Social Psychology, 1968, 9 (Monograph Supplement 2).

\section{NOTE}

1. We are indebted to Harry Schumer and David Senn for help in conducting the experiment and to Alice H. Eagly and George Levinger for their comments on various drafts of this paper. 